\title{
HYPOCARBIA SOON AFTER BIRTH IS NOT ASSOCIATED WITH POOR OUTCOME IN INFANTS TREATED WITH THERAPEUTIC HYPOTHERMIA AFTER PERINATAL ASPHYXIA
}

\author{
H. Sabir, J. Tooley, S. Jary, X. Liu, M. Thoresen \\ School of Clinical Sciences, University of Bristol, St Michael's Hospital, Bristol, UK
}

Background: Most infants affected by perinatal asphyxia are born in poor condition needing resuscitation and ventilatory support after birth. Therapeutic hypothermia reduces brain injury and has become standard of care for these infants. In term and preterm infants that were not cooled, hypocarbia soon after birth was previously associated with poor outcome. We assessed whether hypocarbia is associated with poor outcome in term neonates treated with therapeutic hypothermia.

Methods: Blood gases were analysed in 46 term newborn infants before the onset of therapeutic hypothermia. The effect of hypocarbia $(<4 \mathrm{kPa})$ alone or in combination with hyperoxaemia $(>40 \% \mathrm{O} 2)$ was correlated with poor outcome (death/disability at 18-24months). Poor outcome in survivors were either a Bayley II-MDI or -PDI score $<70$.

Results: Of 46 infants, 14 had poor outcome (10 died). The mean (SD) 10 minute Apgar score was 5.2 (2.9) and worst $\mathrm{pH}$ was $6.9(0.2)$. The mean (SD) HIE grade was $2.4(0.6)$. The median (IQR) lowest pCO2 level was $4.1 \mathrm{kPa}(2.2-12.8 \mathrm{kPa})$ and median (IQR) FiO2 level in the first hour of life was 57\% (21 - 100\%). 23 infants had a pCO2 $<4 \mathrm{kPa}$ (mean 3.1, SD 0.7) and 31 infants had a $\mathrm{FiO} 2>40 \%$ (mean $72.6 \%$, SD 26 ), 15 infants had the combination of hypocarbia+hyperoxaemia. Low $\mathrm{CO} 2$ was not associated with poor outcome neither in combination with low or high FiO2.

Conclusion: Neither hypocarbia alone nor the combination of hypocarbiathyperoxaemia were associated with poor outcome in newborns treated with therapeutic hypothermia. 